\title{
Investigação para Imunodeficiências: quando está indicada e como fazer
}

\author{
Cristina Maria Kokron ${ }^{1}$
}

\section{Resumo}

Infecções de repetição são queixas frequentes no consultório pediátrico sendo que são muito frequentes ou demoram a responder ao tratamento ou são infecções graves. Entretanto, apenas 10\% das crianças com esta queixa poderão apresentar uma deficiência imunológica. Na avaliação do paciente com infecções de repetição, para se fazer a diferenciação entre fatores de risco comuns e distúrbio imunológico, história clínica detalhada, exame físico e eventualmente exames laboratoriais devem ser solicitados. Deve-se levar em consideração dados como numero de infeções, localização, patógenos causadores, resposta ao tratamento instituído e a presença de fatores de risco para infecções, como crianças que frequentam berçários e creches, as que têm irmãos em idade escolar, as fumantes passivas, as portadoras de alergias, defeitos anatômicos das vias respiratórias, doença do refluxo gastroesofágico ou doenças crônicas. A suspeita precoce facilita um diagnóstico precoce e instituição de tratamento adequado para imunodeficiência e consequente redução da morbimortalidade.

Palavras chave: infecções de repetição; imunodeficiências; fatores de risco

Kokron, Cristina Maria. "Investigação para Imunodeficiências: quando está indicada e como fazer", in Anais do 2․ Congresso Internacional Sabará de Especialidades Pediátricas

\footnotetext{
${ }^{1}$ Prof. Colaboradora da Disciplina de Imunologia Clínica e Alergia, Laboratório de Imunologia Clínica e Alergia, LIM-60, HC-FMUSP cmkokron@usp.br
} 
Uma queixa muito frequente nas visitas ao consultório pediátrico são as infecções de repetição. Ao avaliarmos estas crianças, $50 \%$ serão normais, $30 \%$ serão portadores de doenças atópicas, 10\% doentes crônicos e apenas 10\% apresentarão algum tipo de imunodeficiência (Stiehm, 2014). Entretanto, em todas as situações devemos levar em consideração as variações do normal quanto ao número de infecções e os fatores de risco para o aparecimento de infecções tais como: crianças que frequentam berçários e creches, as que têm irmãos em idade escolar, as fumantes passivas, as portadoras de alergias, defeitos anatômicos das vias respiratórias, problemas cardiovasculares, doença do refluxo gastroesofágico ou fibrose cística (Ballow, 2008).

Na hipótese de imunodeficiências, as causas mais comuns de imunodeficiências são adquiridas. Estas são mais frequentemente causadas pela desnutrição e imunossupressão secundária a infecções bacterianas, fúngicas, parasitárias e, particularmente, infecções virais, não só pelo vírus da imunodeficiência humana (HIV), mas também por outros vírus como sarampo e vírus Epstein-Barr. A imunossupressão iatrogênica também é observada em situações de terapias anti-neoplásicas, transplantes de órgãos e administração crônica de corticosteróides.

O marco principal das imunodeficiências primárias é a susceptibilidade aumentada a infecções, entretanto, incidência aumentada de doenças malignas e autoimunes também são fenômenos bem conhecidos em certas imunodeficiências.

Sinais de alerta para imunodeficiências primárias, adaptado ao nosso meio (BRAGID modificado de Jeffrey Modell Foundation, Inc.):

Duas ou mais pneumonias em 1 ano.

Quatro ou mais otites médias em 1 ano.

Estomatites de repetição ou monilíase por mais de 2 meses

Abscessos de repetição ou ectima

Um episódio de infecção sistêmica grave (meningite, osteoartrite, septicemia)

Infecções intestinais de repetição ou diarreia crônica

Asma grave, doença do colágeno ou doença autoimune

$\square$ Efeito adverso ao BCG e/ou infecção por micobactérias

$\square$ Fenótipo clínico sugestivo de síndrome associada a imunodeficiência

História familiar de imunodeficiência

No primeiro ano de vida, outros sinais podem ser sugestivos como: presença de cardiopatias congênitas, diabetes mellitus ou outras doenças autoimunes e inflamatórias, linfopenia $<2500$ células/mm3, hipocalcemia com ou sem convulsão e ausência de sombra tímica no RX (CarneiroSampaio, 2011). 
Originalmente, as imunodeficiências primárias eram vistas como doenças raras, caracterizadas por expressão clínica grave de início precoce. Entretanto, hoje dois aspectos ficaram mais evidentes: são patologias não tão raras quanto se acreditava inicialmente e a sua frequência é praticamente a mesma entre adolescentes e adultos como em crianças e lactentes. Estima-se que nos EUA nascem aproximadamente 1 em cada 1.200 indivíduos com defeito em algum componente do sistema imune, mas apenas uma pequena porcentagem tem defeitos que poderiam determinar complicações com risco de morte (Boyle et al, 2007).

A distribuição das imunodeficiências primárias na América Latina está demonstrada na figura abaixo. Esta distribuição é semelhante à observada em outras casuísticas.

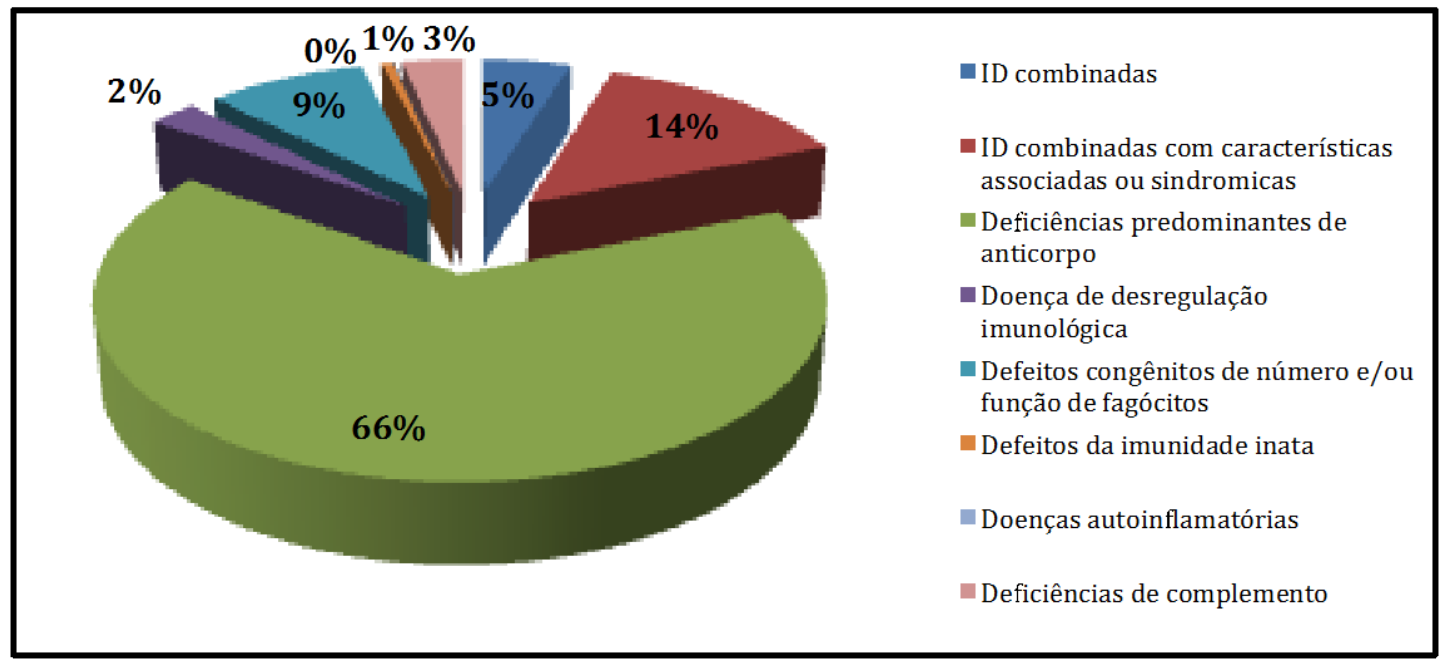

Figura 1: Distribuição das imunodeficiências primárias na América Latina (LASID, agosto 2014).

Como se pode observar na figura 1 , mais da metade das imunodeficiências primárias são decorrentes de alterações na produção de anticorpos. Entretanto, isto é fato apenas a partir dos 3-4 anos de idade. A figura 2 mostra a distribuição das IDPs de acordo com a faixa etária (CarneiroSampaio, 2013). Este dado é relevante, pois, frente a um paciente com infecções de repetição diversos fatores devem ser levados em consideração, como idade de inicio das manifestações, local das infecções, tipos de microorganismos causadores das infecções, alterações no exame físico, entre outros. 


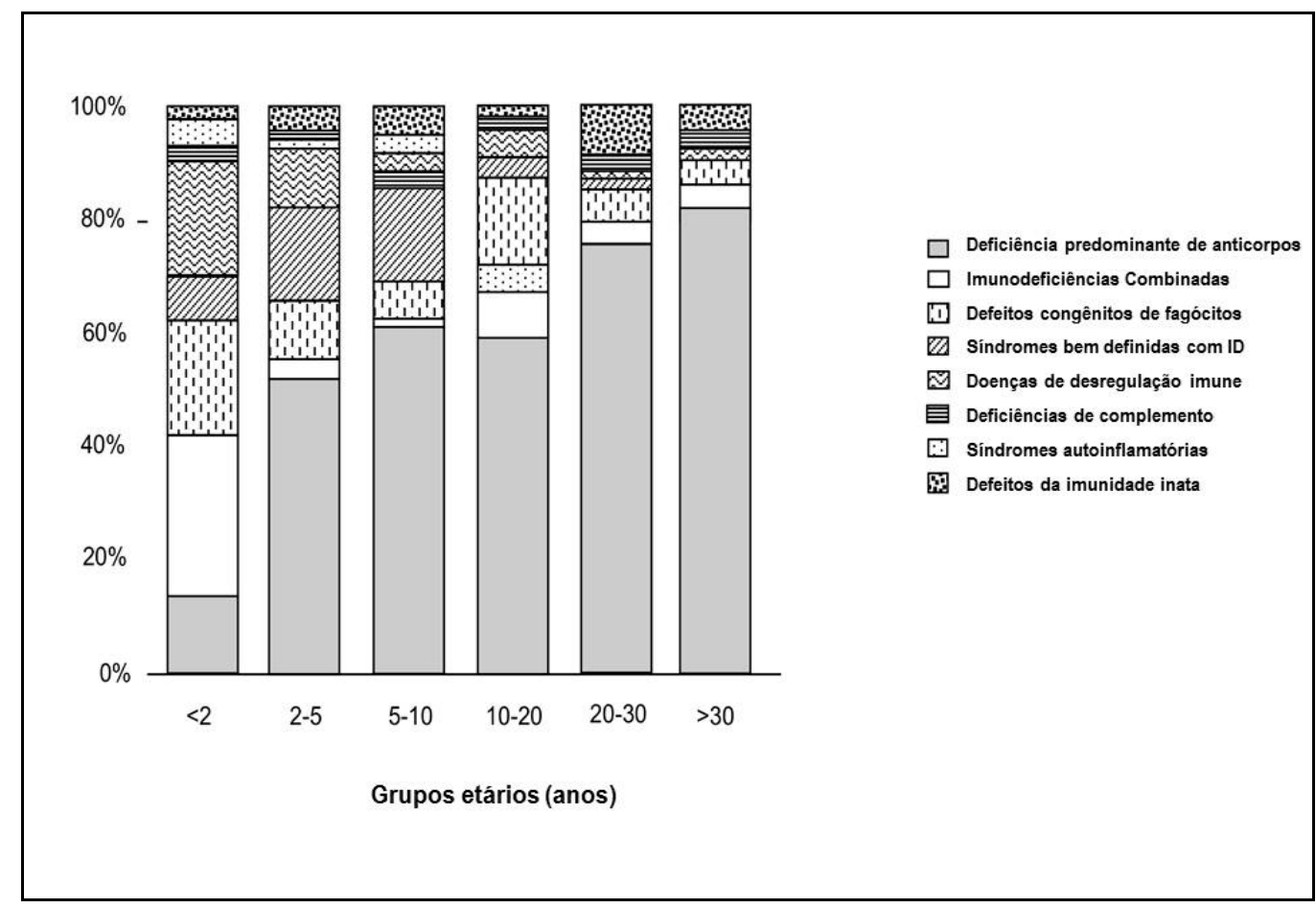

Figura 2: Distribuição das imunodeficiências primárias nas diferentes faixas etárias no complexo HCFMUSP.

\section{Avaliação inicial}

\section{Dados da História Clínica:}

1. Idade de início das infecções: De um modo geral, quanto mais cedo o início das infecções, mais grave a imunodeficiência.

Até 6 meses: Imunodeficiência Combinada Severa (SCID), neutropenia congênita grave, síndrome de DiGeorge, deficiência de adesão leucocitária.

6-12 meses: SCID, outras deficiências combinadas, deficiência de CD40L.

6/12m-5 anos: S. Wiskott-Aldrich, S. DiGeorge, deficiências de anticorpos, candidíase mucocutanea crônica, doença granulomatosa crônica

>5 anos: apresentação tardia das anteriores, ataxia-telangiectasia, imunodeficiência comum variável, defeito de anticorpo específico, defeitos de complemento.

\section{Localização e microbiologia da infecção:}

A localização das infecções é importante para se determinar a importância destas infecções e também sugerir a fisiopatologia do defeito imunológico. Otites médias, sinusites, pneumonias, gengivites, meningites, septicemia, infecções de pele e abcessos são localizações frequentemente associados a 
alguma imunodeficiência. Outras como faringites de repetição, dificilmente estarão associadas a deficiências do sistema imune. Gengivites de repetição podem estar associadas a defeitos dos neutrófilos ou neutropenia, septicemias sugerem defeito de opsonização.

Infecções virais graves, infecções por fungos, micobactérias, protozoários ou infecções oportunistas, sugerem defeitos da imunidade celular.

Início precoce com infecções graves, predominantemente bacterianas - além das hipóteses acima considerar também defeitos do sistema fagocitário e do complemento.

Infecções sinopulmonares recorrentes de origem bacteriana, em geral bactérias encapsuladas iniciar com avaliação humoral. Giardíase é frequente na deficiência de IgA e imunodeficiência comum variável. Infecções recorrentes por bactérias de baixa virulência sugerem anormalidade dos neutrófilos. Infecções recorrentes por bactérias do gênero Neisseria são altamente sugestivas de deficiências do sistema complemento que comprometem as frações terminais (C5, C6, C7 e C8).

\section{História familiar:}

Muitas imunodeficiências são hereditárias, portanto atenção especial deve ser dada a história familiar. Várias imunodeficiências têm sua herança ligada ao sexo masculino, como agamaglobulinemia de Bruton, síndrome de hiperIgM ligada ao X, doença granulomatosa crônica ligada ao X. História de consangüinidade levanta a possibilidade de uma doença autossômica recessiva. A deficiência de IgA e a imunodeficiência comum variável são familiares e muito frequentemente observadas em famílias onde outros membros apresentam patologias autoimunes.

4. Outros dados importantes para história: dados do nascimento, crescimento e desenvolvimento, histórico de vacinação e suas complicações, medicações, outras doenças, história social.

\section{Dados do Exame físico:}

O exame físico não só pode mostrar sinais que comprovam a história prévia de infecções do paciente, como também existem várias imunodeficiências que estão associadas a certas anormalidades físicas e/ou dismorfismos. Atenção especial deve ser dada ao atraso do crescimento e desenvolvimento, perda de peso, aumento ou ausência de linfonodos, organomegalia, dermatite, teleangiectasia, petéquias, anormalidades faciais, anormalidades cardíacas, candidíase oral, baixa estatura, alterações neurológicas e musculoesqueléticas.

1- Defeito anatômico ou obstrutivo - defeito não imunológico da defesa do indivíduo

2- Síndromes específicas: Pacientes com infecções de repetição, acompanhados de:

-fácies anormal, defeito cardíaco e hipocalcemia sugerem Síndrome de DiGeorge

-Atraso do desenvolvimento motor e ataxia, pensar em ataxia-teleangiectasia 
-Eczema e trombocitopenia sugerem Síndrome de Wiskott-Aldrich

-Albinismo parcial óculo-cutâneo e defeitos neurológicos, pensar em Síndrome de Chediak-Higashi -Anemia hemolítica - pensar em deficiência de G6PD

\section{Avaliação Laboratorial Inicial:}

A avaliação inicial inclui hemograma completo, dosagem de imunoglobulinas e testes de hipersensibilidade tardia, que já fornecem um panorama sobre o estado imunológico do paciente.

Um simples hemograma completo com diferencial pode mostrar dados como:

neutropenia $\left(<1500 / \mathrm{mm}^{3}\right)$ - investigar neutropenias

linfopenia - investigar deficiência de células T

plaquetopenia - associado a alterações de tamanho está presente na Síndrome de WiskottAldrich

A morfologia dos leucócitos e seus grânulos pode mostrar a presença de corpos de HowellJolly - (asplenia funcional); grânulos anormais (considerar deficiência específica de grânulos).

De acordo com a suspeita diagnóstica, podem ser solicitados exames mais específicos conforme apresentados na Tabela 1.

O diagnóstico de certeza da imunodeficiência deve ser estabelecido por meio de técnicas de biologia molecular sempre que possível.

Tabela1: Avaliação laboratorial básica de um paciente com suspeita de Imunodeficiência.

\begin{tabular}{|c|c|c|}
\hline & Avaliação inicial & Avaliação adicional \\
\hline \multirow[t]{2}{*}{ Imunidade humoral } & Dosagem de IgG, IgA, IgM & $\begin{array}{l}\text { Quantificação de linfócitos B, } \\
\text { dosagem de IgE }\end{array}$ \\
\hline & $\begin{array}{l}\text { Dosagem de anticorpos específicos a antígenos } \\
\text { vacinais ou infecções naturais; } \\
\text { Dosagem de subclasses de IgG; } \\
\text { quantificação de isohemaglutininas para avaliação da } \\
\text { função de IgM (exceto em indivíduos do grupo } \\
\text { sanguíneo AB) }\end{array}$ & $\begin{array}{l}\text { Dosagem de anticorpos para } \\
\text { sorotipos de pneumococo pré e pós } \\
\text { vacinação }\end{array}$ \\
\hline \multirow[t]{2}{*}{ Imunidade celular } & Quantificação de linfócitos & $\begin{array}{l}\text { Imunofenotipagem das } \\
\text { subpopulações linfocitárias }\end{array}$ \\
\hline & Testes cutâneos de hipersensibilidade tardia & $\begin{array}{l}\text { Cultura de linfócitos com } \\
\text { mitógenos e antígenos }\end{array}$ \\
\hline Avaliação de fagócitos & $\begin{array}{l}\text { Determinação do número e aspecto morfológico de } \\
\text { neutrófilos e monócitos, } \\
\text { Dosagem de IgE }\end{array}$ & $\begin{array}{l}\text { teste de oxidação de DHR, teste do } \\
\text { NBT, fagocitose }\end{array}$ \\
\hline $\begin{array}{l}\text { Avaliação do sistema } \\
\text { complemento }\end{array}$ & $\begin{array}{l}\text { CH50 (via clássica), } \\
\text { AP50 (via alternativa), } \\
\text { C3, C4 }\end{array}$ & $\begin{array}{l}\text { Dosagem individual de cada } \\
\text { proteína do sistema complemento }\end{array}$ \\
\hline $\begin{array}{l}\text { Radiologia de tórax e } \\
\text { cavum }\end{array}$ & Avaliação do timo e tecido linfóide & \\
\hline Pesquisa para HIV & Sorologia e/ou PCR & \\
\hline
\end{tabular}


Adaptado de Oliveira e Kokron, Imunodeficiências Primárias: diagnóstico e tratamento, In livro Diagnóstico e Tratamento das Doenças Imunológicas, Schainberg \& Geller. Elsevier. 2a ed in press.

\section{Investigation for immunodeficiencies: when and how?}

\section{Abstract:}

Recurrent infections are frequent complains at the pediatrician's office. Infections are too frequent, too long lasting or too severe. However, only $10 \%$ of the children with recurrent infections will present an immune dysfunction. To differentiate children with common risk factors for recurrent infections from those with immunodeficiency, a thorough clinical history and physical exam, and eventually some lab tests will be needed. Information like number and site of infections, their microbiology, response to treatment and the presence of risk factors for infections like being in a daycare or siblings in school age, passive smoking, presence of allergies, anatomic defects in upper or lower airways, gastroesophageal reflux or chronic diseases should be evaluated. Precocious suspicion helps early diagnosis and treatment of immunodeficiency with consequent reduction in morbidity and mortality.

Keywords: recurrent infections, immunodeficiency, risk factors

\section{Referências}

Ballow M. Approach to the patient with recurrent infections. Clin Rev Allergy Immunol. 2008 Apr;34(2):129-40. doi: 10.1007/s12016-007-8041-2.

Barreto AK, Kokron CM. Capitulo 31 - Imunodeficiências Primárias: Diagnóstico e Tratamento. In livro Diagnóstico e Tratamento das Doenças Imunológicas, Schainberg \& Geller. Elsevier. 2a ed. In press.

Bonilla FA; Stiehm ER. Laboratory evaluation of the immune system. www.uptodate.com ; tópico atualizado em 2/7/2013. Stiehm ER. Approach to the child with recurrent infections. www.uptodate.com ; tópico atualizado em 30/07/2014.

Boyle JM, Buckley RH. Population prevalence of diagnosed primary immunodeficiency diseases in the United States. J Clin Immunol, 27:497-502, 2007.

BRAGID, Grupo Brasileiro de Imunodeficiências, www.imunopediatria.org.br

Carneiro-Sampaio M, Jacob CM, Leone CR. A proposal of warning signs for primary immunodeficiencies in the first year of life. Pediatr Allergy Immunol. 2011;22(3):345-6.

Carneiro-Sampaio M, Moraes-Vasconcelos D, Kokron CM, Jacob CM, Toledo-Barros M, Dorna MB, Watanabe LA, Marinho AK, Castro AP, Pastorino AC, Silva CA, Ferreira MD, Rizzo LV, Kalil J, 
Duarte AJS. Primary Immunodeficiency Diseases in Different Age Groups: A Report on 1,008 Cases from a Single Brazilian Reference Center. J Clin Immunol, 33:716-724, 2013. 